\title{
CORRESPONDENCE
}

\section{Sedentary versus inactive: distinctions for disease prevention}

\author{
Brigid M. Lynch, Genevieve N. Healy, David W. Dunstan and Neville Owen
}

We read with great interest the Perspectives article from Charansonney and Després in the August 2010 issue of Nature Reviews Cardio$\log y$ (Charansonney, O. L. \& Després, J. -P. Disease prevention-should we target obesity or sedentary lifestyle? Nat. Rev. Cardiol. 7, 468-472 (2010)). ${ }^{1}$ This paper puts forward an innovative model providing a framework for understanding some of the physiological consequences of sedentary behavior. We agree with many aspects of what is proposed. However, as the group that has conducted many of the initial studies identifying the unique health consequences of sedentary behavior, we are concerned that aspects of the Charansonney and Després model might perpetuate the misconception that sedentary behavior is simply 'one end of the physical activity continuum. That is, people can be classified as either 'active' or 'sedentary' based on their self-reported or objectively assessed physical activity.

The contemporary understanding of sedentary behavior is that it is not merely the absence of health-enhancing physical activity in everyday life. Sedentary behavior is characterized by prolonged sitting or reclining and the absence of whole-body movement. Sedentary behavior has deleterious health consequences that are distinct from the lack of physical activity of moderateto-vigorous intensity. Put simply, sedentary behavior and physical inactivity are two separate and independent attributes, each with distinct health consequences.

In their model, Charansonney and Després propose that individuals who have a sedentary lifestyle exhibit a hypothesized inappropriate stress response, whereas those who have an active lifestyle are not exposed to the cascade of deleterious effects. However, we have demonstrated significant, detrimental associations of sedentary behavior with a range of cardiometabolic biomarkers in adults meeting physical activity guidelines. ${ }^{2}$ The Charansonney and Després model does not account for the fact that many people who engage in vigorous-intensity physical activity on a daily basis, and hence have high levels of cardiorespiratory fitness, also engage in prolonged periods of sitting throughout their day.

We believe that model put forward by Charansonney and Després supports a strong potential biological plausibility for many of the deleterious associations that we and others have shown to be associated with sedentary behavior. However, we would argue that the model must be considered in a broader context, taking into account how sedentary behavior can coexist with high levels of both physical activity and cardiorespiratory fitness.

Department of Population Health Research, Alberta Health Services-Cancer Care, 1331 $29^{\text {th }}$ Street NW, Calgary, AB T2N 4N2, Canada (B. M. Lynch). The University of Queensland, St Lucia, Brisbane, QLD 4072, Australia (G. N. Healy, N. Owen). Baker IDI Heart and Diabetes Institute, 75 Commercial Road, Melbourne, VIC 3004, Australia (D. W. Dunstan).

Correspondence to: B. M. Lynch brigid.lynch@albertahealthservices.ca doi:10.1083/nrcardio.2010.68-c1

Competing interests

The authors declare no competing interests.

1. Charansonney, O. L. \& Després, J. P. Disease prevention-should we target obesity or sedentary lifestyle? Nat. Rev. Cardiol. 7, 468-472 (2010).

2. Healy, G. N. et al. Television time and continuous metabolic risk in physically active adults. Med. Sci. Sports Exerc. 40, 639-645 (2008). 